DOI: $10.14451 / 2.122 .82$

\title{
АНАЛИЗ ТЕКУЩИХ ЗАДАЧ ГЕОЛОГОРАЗВЕДОЧНОЙ ОТРАСЛИ РОССИЙСКОЙ ФЕДЕРАЦИИ И АКТУАЛЬНОСТЬ ТРАНСФОРМАЦИИ СЕКТОРА ДЛЯ ПРОГРЕССИВНОГО РАЗВИТИЯ
}

\author{
(c) 2018 Лютягин Дмитрий Владимирович \\ доцент, кандидат экономических наук \\ кафедра Экономики минерально-сырьевого комплекса \\ Российский государственный геологоразведочный университет им. Серго Орджоникидзе \\ 117485, Россия, г. Москва, ул. Миклухо-Маклая, 25 \\ E-mail:1-d-v@list.ru \\ (c) 2018 Забайкин Юрий Васильевич \\ доцент, кандидат экономических наук \\ кафедра Экономики минерально-сырьевого комплекса \\ Российский государственный геологоразведочный университет им. Серго Орджоникидзе \\ 117485, Россия, г. Москва, ул. Миклухо-Маклая, 25 \\ E-mail: 79264154444@yandex.com
}

Реальная экономика РФ в значительной мере ориентирована на использование полезных ископаемых. При этом в последние десятилетия в стране сложилась ситуация, при которой восполнения ресурсов практически не происходит. Такое положение чревато возникновением серьезных проблем как в области промышленного производства, так и в социальной области. Именно поэтому глубокую озабоченность вызывает современное состояние дел в геологоразведочной отрасли, обеспечивающей потенциал развития данного сектора экономики. В статье рассмотрены основные причины снижения темпов воспроизводства запасов минеральных ресурсов и вызовы, с которыми сталкивается геологоразведочная отрасль в своем современном развитии. На основании анализа предлагается ряд мероприятий, направленных на обеспечение поступательного развития геологоразведочной отрасли.

Ключевые слова: полезные ископаемые, ресурсы, геологоразведочные работы, государственное регулирование, инвестиционная привлекательность, воспроизводство минерально-сырьевой базы.

Для оценки целесообразности и степени важности преобразований в области ресурсообеспеченности РФ необходимо, в первую очередь, иметь ясное представление о перспективах востребованности того или иного вида полезных ископаемых в будущем. При этом необходимо иметь в виду, что полезные ископаемые по своей сути относятся к «исчерпаемым и невозобновляемым» ресурсам, а ресурсообеспеченность ими оценивается соотношением объемов разведанных запасов и объемами их добычи и использования. Существенным в области ресурсообеспеченности на стратегическую перспективу является также развитие направления рационального использования недр, без этой составляющей не будет целостной картины стратегического развития страны в области минерального сырья [5].

Современный этап постиндустриального развития общества характеризуется существен- ными изменениями подходов к использованию природных ресурсов, в том числе в их невосполнимой части. Это не может не наложить своего отпечатка на изменение тенденций востребованности тех или иных полезных ископаемых. В наибольшей степени это относится к области энергетики. Попытки предотвратить неминуемый дефицит невосполнимых запасов энергоносителей привели к развитию целого ряда проектов, основанных на восполняемых источниках энергии (использование энергии ветра, воды, солнца, термальных источников и так далее) и на развитии инновационных методах добычи с тем, чтобы увеличить извекаемость имеющихся запасов. Тем не менее, дефицит энергоносителей имеет место практически по всему миру и в обозримой перспективе использование углеводородного сырья, как источника энергии, будет продолжаться все в возрастающих объемах. По мнению министерства энергетики США 
(U.S. Department of Energy), в течение по меньшей мере 25 ближайших лет главным источником энергии в мире останется именно нефть. Так, к 2040 году из нее будет вырабатываться не менее 30\% мирового объема энергии. При этом доля снижения ее потребления по сравнению с текущим уровнем не превысит $3 \%$. Что же касается природного газа, то темпы роста его потребления будут самыми высокими среди углеводородов [14].

Учитывая вышесказанное, чрезвычайно важным представляется анализ текущего состояния дел по обеспечению ресурсами народного хозяйства РФ. В частности, одним из наиболее важных аспектов данной проблемы является воспроизводство минерально-сырьевой базы (МСБ). МСБ - это полезные ископаемые в виде месторождений, которые могут быть вовлечены в сферу общественного производства [1]. Воспроизводство же, в классическом его понимании - это воссоздание израсходованных факторов производства (природных ресурсов, средств производства) посредством их последующего производства [11].

Именно проблемы с воспроизводством МСБ как раз и являются наиболее очевидными для современной России. Суть этих проблем заключается в чрезвычайно интенсивном развитии добывающих отраслей, ресурсной базой для которых являются запасы полезных ископаемых, созданные еще в советское время. Одним из следствий такого положения дел является повышенный риск, который ложится на компании, приобретающие лицензии на право пользования недрами на самых ранних стадиях геологической изученности месторождений [15]. В результате многие компании вынуждены вкладывать средства в доразведку месторождений, полученных в рамках лицензии, а не в открытие новых. Важно иметь в виду, что воспроизводство МСБ может быть достигнуто как путем совершенствования технологий добычи, интенсификации и масштабному внедрению инновационных способов добычи, так и за счет геологоразведочных работ (ГРР). Расширение же ресурсной базы обеспечивается исключительно увеличением объемов поисково-разведочных работ и доразведкой перспективных ресурсных участков [11].

Различие подходов к интерпретации оптимального соотношения между необходимыми объемами запасов минеральных ресурсов и тем- пами их добычи и проблем воспроизводства МСБ можно свести к следующим основным положениям:

- Количество разведанных запасов минеральных ресурсов вполне обеспечивает функционирование промышленного производства и экспортные потребности. Широкомасштабное проведение ГРР может быть отложено на неопределенный период.

- Усилия следует направить на более рациональное использование потенциала «старых» месторождений. При этом развитию поисково-разведочных работ отводится вспомогательная роль.

- Восполнение МСБ возможно только за счет широкомасштабных поисково-разведочных мероприятий в новых, недостаточно исследованных в предыдущий период районах.

- Интенсивность и методологическая направленность ГРР требуют региональной дифференциации. При этом в регионах с развитой инфраструктурой добычи должно осуществляться расширенное воспроизводство МСБ за счет применения новых методов разведки. В новых же, перспективных районах, в настоящее время достаточно провести ограниченные поисково-разведочные работы, которые призваны обеспечить задел для развития минерально-сырьевой базы в последующий период [6].

Следует отметить, что ни одна из приведенных точек зрения по существу не имеет строгого научного обоснования. В СССР соотношение между объемами запасов и добычи определялось регламентированным превышением прироста запасов над планируемым уровнем добычи. Так, в качестве примера рассмотрим нефтедобычу, в соответствии с рекомендациями Госплана [7] превышение запасов нефти категорий A, B, C1 над планируемым уровнем добычи должно было быть 25-30-кратным. Именно такая методика использовалась при разработке плановых показателей отрасли в 70-80-е годы прошлого века. Последующая практика показала несостоятельность такого подхода [14].

Полезно обратиться к анализу ситуации с обеспеченностью сырьевой базой крупнейших отечественных и зарубежных нефтедобывающих компаний (рис. 1). Очевидно, что современное состояние сырьевой базы нефтедобывающих компаний далеко от параметров, рекомендованным некогда Госпланом. Тем не менее, даже и в таком «урезанном» виде задача обеспечения 


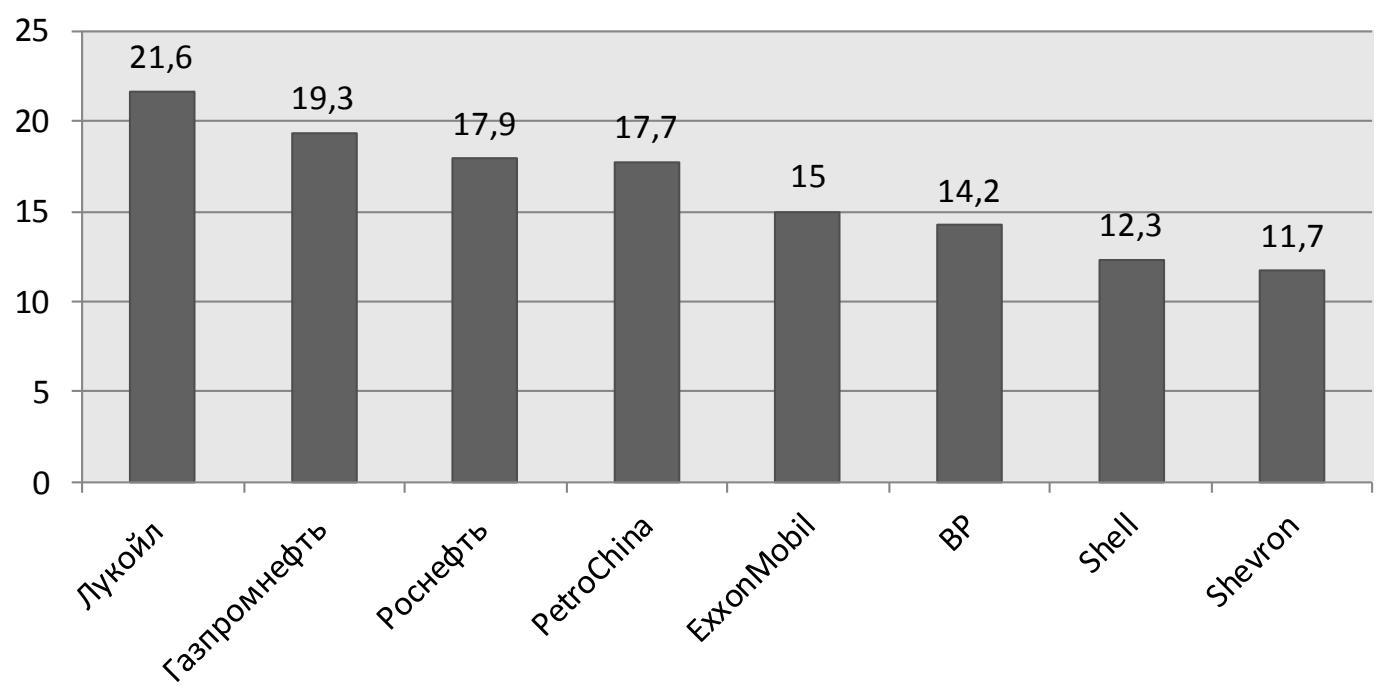

Puc. 1. Фактическая кратность запасов по основным нефтедобывающим компаниям Источник: составлено автором по данным [13].

сырьевыми ресурсами добывающей и перерабатывающей промышленности становится все более трудновыполнимой.

Проблема существенного снижения темпа обеспеченности добывающей промышленности соответствующей сырьевой базой носит интернациональный характер. Динамика изменения соотношения между объемами добычи нефти в мире и темпами прироста ее разведанных запасов (рисунок 2) свидетельствует, что, начиная с 1984 года, возник разрыв в данном соотношении, который усугубляется и по сей день. Не лучшим образом обстоят дела и в РФ. Как отме- чается в [12], начиная с 2005 года объем добычи таких полезных ископаемых, как газа, золота, угля, нефти, железных руд существенно превышает прирост их запасов. В отношении таких полезных ископаемых как уголь, черные металлы и пр., ситуация с восполнением и развитием минерально-сырьевой базы еще сложнее, т.к. эти полезные ископаемые менее экспортоориентированные чем нефть и имеют меньшую маржинальность, что соответственно не подстегивает компании к расширенному воспроизводству этого сырья. При этом новых значимых открытий практически не совершается, а при-

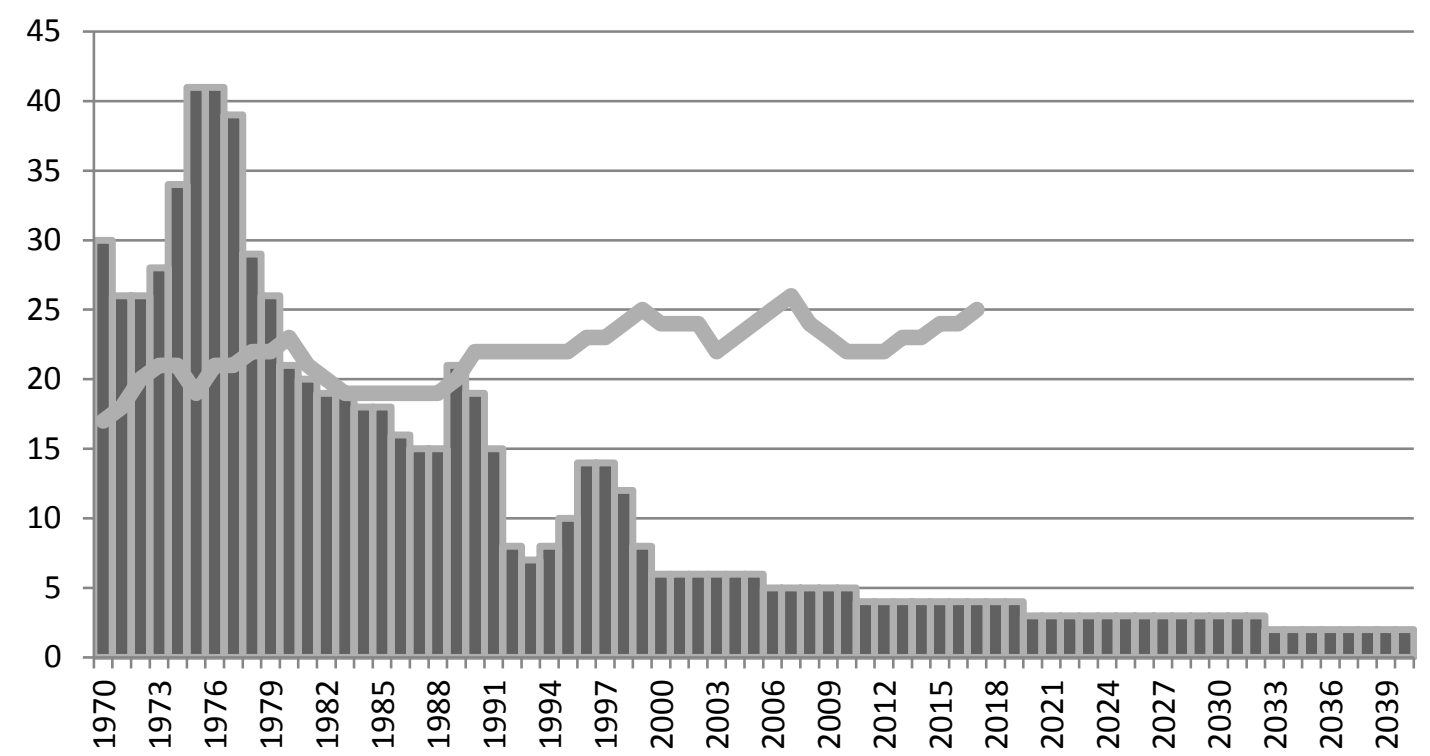

Годовой объем мировой нефтедобычи, млрд. баррелей в год

Объем разведанных запасов (погодично), млрд. баррелей

Puc. 2. Динамика соотношения темпов добычи и разведки запасов нефти в мире Источник. Составлено автором по данным Hughes GSR Inc. 
рост добычи получается, в основном, на ранее открытых месторождениях путем их доразведки по контуру. Сам же прирост запасов по промышленным категориям составляет всего лишь около 5\% от годового прироста добычи. Можно назвать несколько значимых, на наш взгляд, причин создавшегося положения:

- Ослабление влияния государства на формирование минерально-сырьевой базы.

В СССР проведение ГРР было прерогативой Министерства геологии. При этом все работы осуществлялись исключительно за счет бюджетных средств. В настоящее же время основные расходы на восстановление ресурсной базы ложатся на плечи недропользователей (рисунок 3)
[3].

Следствием указанного ослабления стало хроническое недофинансирование отрасли в целом и существенное снижение объемов поисково-разведочного бурения в частности (рисунок 4). Причиной этого является, на наш взгляд, снижение инвестиционной привлекательности геологоразведочных работ. Так, по свидетельству авторов [12] еще в 2010 г. Президент ПАО «ЛУКОЙЛ» В.Ю. Алекперов заявил о снижении на 65\% инвестиций в геологоразведку. Причинами такого шага он назвал существующий порядок, при котором разведанные месторождения передаются государству, а не недропользователю, совершившему открытие. Кроме того, затраты на

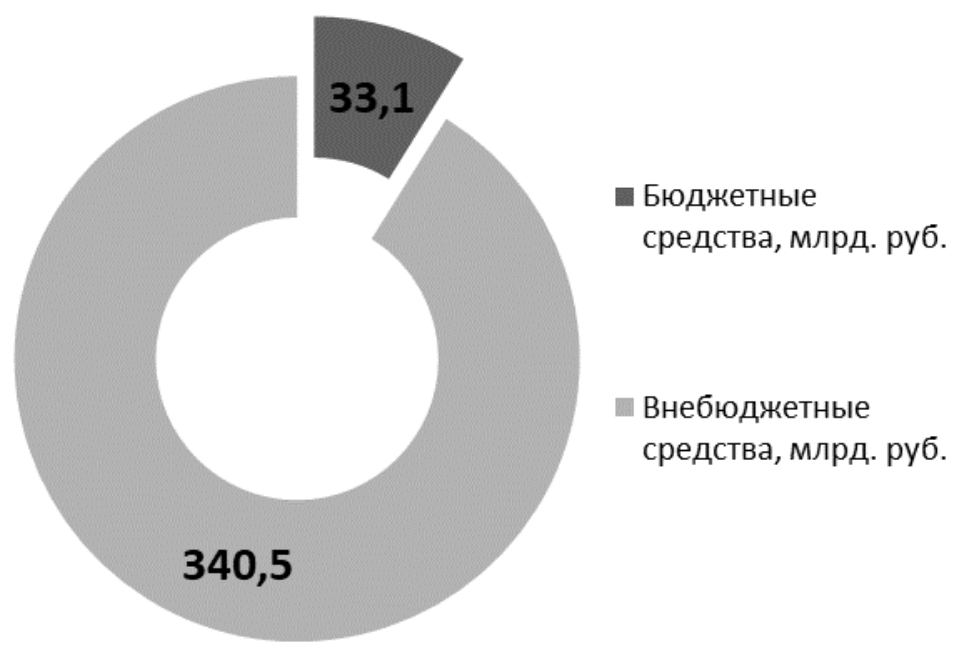

Рuc. 3. Распределение затрат при реализации программы «Воспроизводство минерально-сырьевой базы, геологическое изучение недр» в 2017 г.

Источник. Составлено автором по данным государственного доклада Министерства природных ресурсов и экологии РФ.

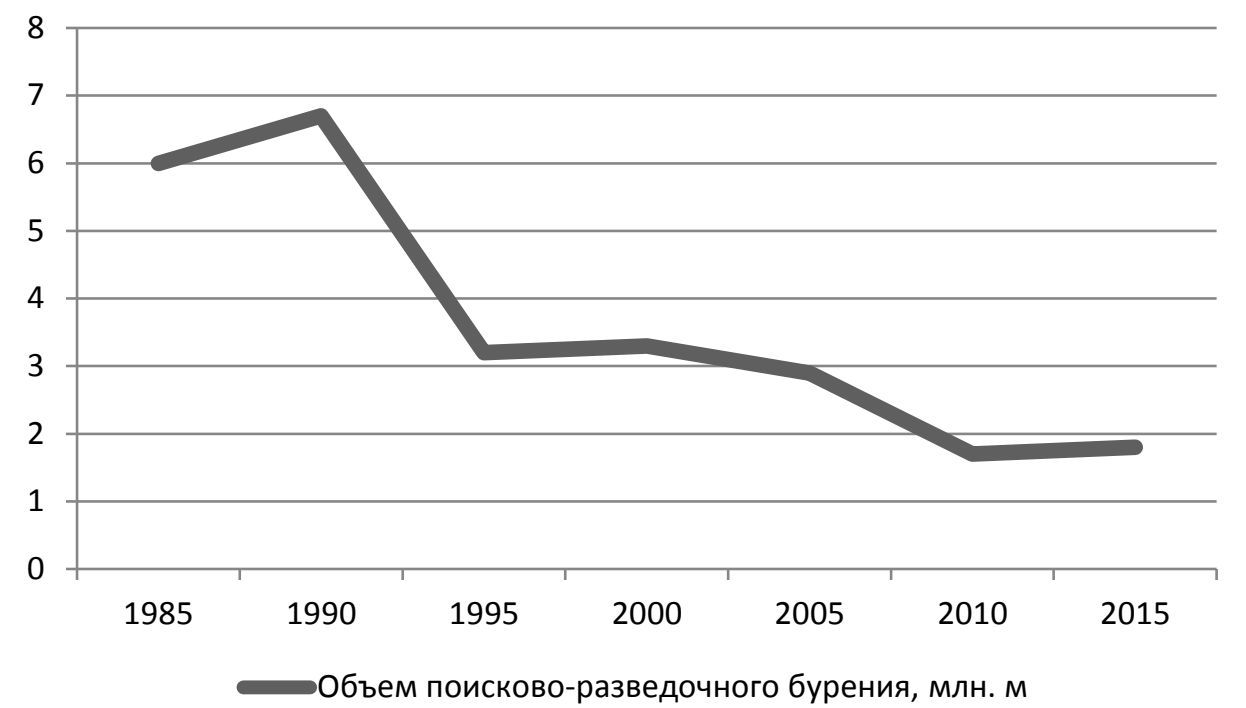

Puc. 4. Динамика изменения объемов поисково-разведочного бурения в России Источник: Составлено автором по данным [13]. 
производство ГРР подлежат возмещению только в случае их завершения с положительным результатом. О том же, по существу, говорится и в «Стратегии развития геологической отрасли до 2030 года» [10] где, наряду с другими факторами, сдерживающими развитие минерально-сырьевой базы, отмечается тот факт, что «действующая система государственного регулирования отношений недропользования не создает достаточных условий для привлечения инвестиций недропользователей в геологоразведочные работы».

В этом свете показательным является сравнение относительной доли доходов отечественных и зарубежных добывающих компаний, направляемых на компенсацию запасов (рисунок 5). Совершенно очевидно, что существенное различие в объемах средств, направляемых на эти цели зарубежными и отечественными компаниями, как раз и является следствием разного подхода к мотивации такого рода вложений.

- Существенное изменение структуры сырьевых запасов.

К числу показателей, характеризующих указанные изменения, можно отнести следующие:

- Истощение запасов в традиционных районах добычи.
- Сокращение размеров запасов вновь открываемых месторождений. За последние полвека произошло снижение средних запасов открываемых в России нефтяных месторождений более, чем в 30 раз.

- Значительный рост доли трудно извлекаемых запасов (ТИЗ). Данный вид углеводородного сырья является важным резервом пополнения ресурсов. В настоящее время доля ТИЗ в общем балансе запасов углеводородного сырья в России составляет более 65\% [10]. При этом, по мере выработки традиционных запасов, доля ТИЗ будет непрерывно расти и надо учитывать, что экономически эффективная технология добычи ТИЗ в этом случае требует использования принципиально иных, значительно более затратных и наукоемких методов.

- Общее снижение коэффициента извлечения нефти (КИН). Указанное снижение является одним из следствий отмеченного выше увеличения доли ТИЗ в структуре запасов. Данный показатель в настоящее время снизился до уровня 0,3 по сравнению со средним значением 0,45, который имел место в советский период.

- Усложнение горно-геологических и географических условий открытия и освоения новых месторождений. Данный аспект изменений

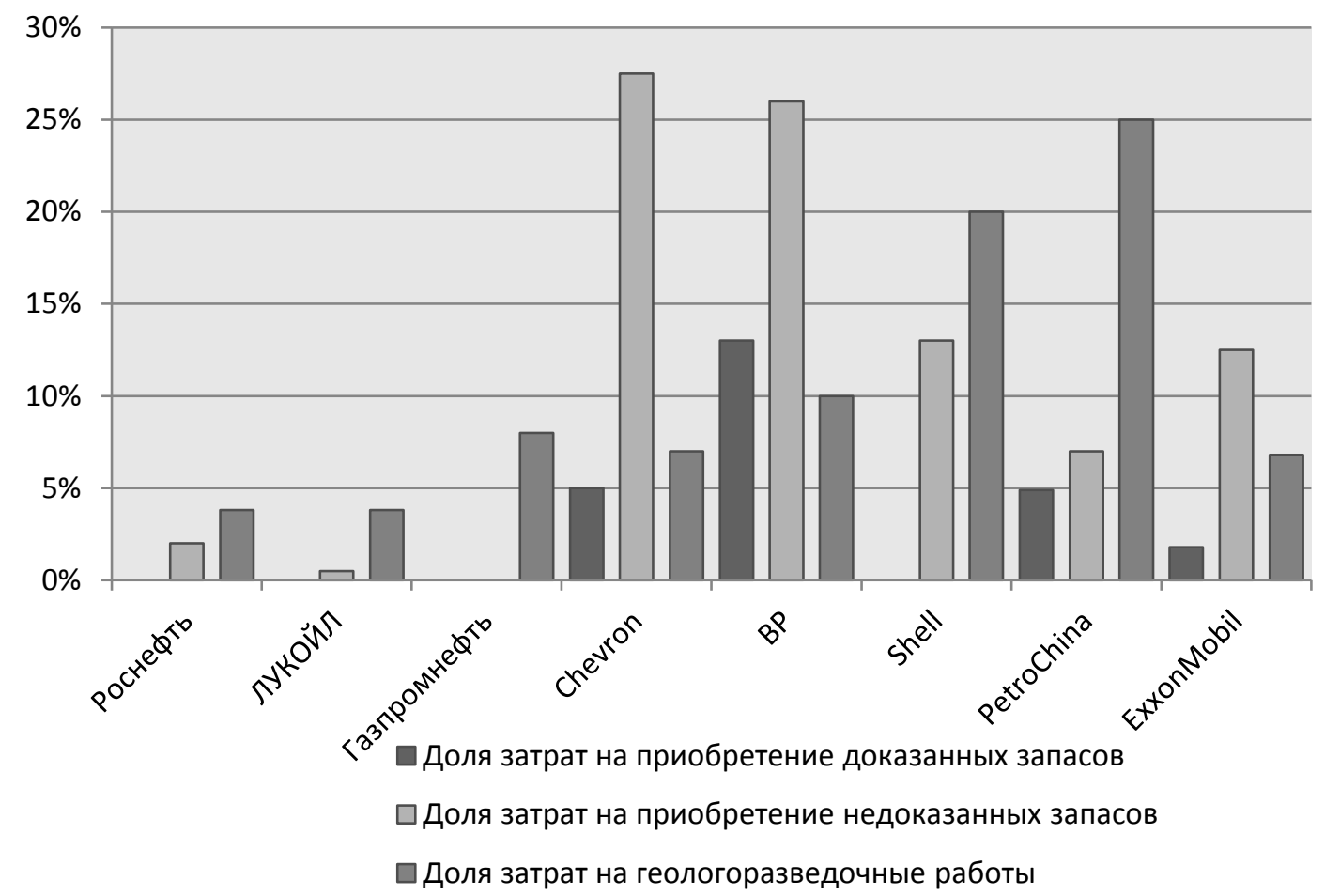

Puc. 5. Сравнение затрат добывающих компаний на компенсацию запасов нефти, в\% от чистой прибыли. Источник. Составлено автором по данным [13] 


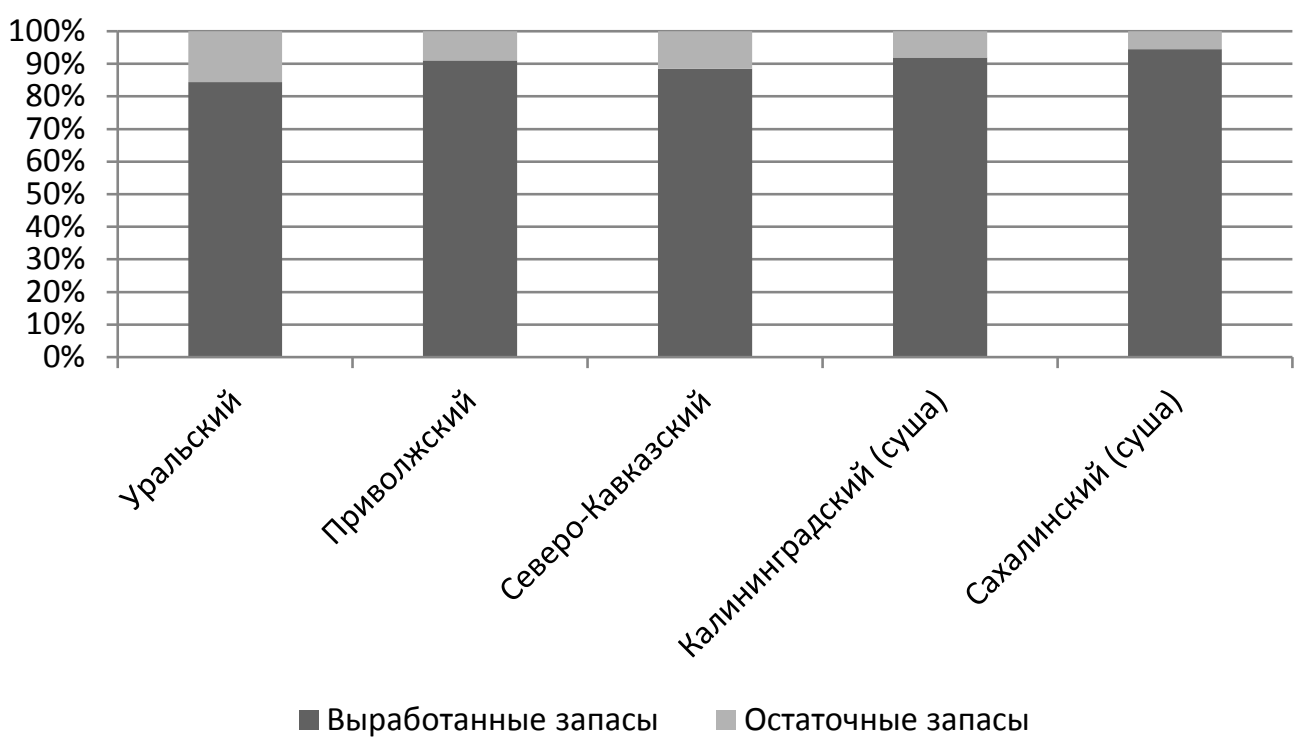

Puc. 6. Степень выработанности нефтяных месторождений по регионам России Источник: составлено автором по данным [13]

структуры сырьевых запасов сопровождается также увеличением территориального разрыва между районами добычи сырья и его потреблением.

На протяжении последних полутора десятилетий добывающая промышленность и геологоразведочный сектор России в целом развивались в соответствии с международными тенденциями. Тем не менее, поскольку по большинству полезных ископаемых прирост их запасов не восполняет объемы добычи, а поступления в государственный бюджет формируются, в основном, именно за счет добывающих отраслей, опережающее развитие системы воспроизводства минеральных ресурсов является решающим условием динамичного развития российской промышленности и общества в целом.

В соответствии со «Стратегией развития геологической отрасли до 2030 г.» [10] предполагается перевести геологическую отрасль России на качественно новый уровень. В число задач, поставленных перед холдингом, входят следующие:

- повысить к 2020 году уровень изученности территории РФ до 50\%;

- к этому же сроку предстоит повысить до 60\% уровень изученности территорий РФ, подверженных влиянию опасных процессов и явлений;

- обеспечить рост объемов финансирования за счет внебюджетных источников на $40 \%$ к 2020 году;
- осуществить законодательные реформы, обеспечивающие закрепление права недропользователей на разработку месторождений, открытых в ходе осуществляемых ими геологоразведочных работ.

Успешность выполнения поставленных задач во многом зависит от того, насколько слаженными и эффективными будут совместные действия всех сторон, участвующих в выполнении поставленной задачи. При этом в настоящий же момент можно выделить целый ряд факторов, которые так или иначе препятствуют развитию геологоразведочных работ в России.

- Отсутствие стимулирования и государственной поддержки при проведении ГРР.

В соответствии с действующим Налоговым кодексом РФ проведение любых ГРР может осуществляться только за счет прибыли предприятия-недропользователя. В то же время в развитых добывающих странах практикуется иная система, при которой указанные затраты входят в состав себестоимости продукции.

- Чрезвычайно сложная и трудоемкая система получения и передачи прав пользования участками недр.

К числу недостатков действующей системы следует отнести невозможность права пользования недрами служить предметом сделки между участниками рынка, низкий уровень защищенности имущественных прав на участках недр (право пользования недрами может быть прекращено помимо решения суда), чрезвычайно 
длительная, трудоемкая и затратная процедура аукционов.

- Ограниченные возможности привлечения банковского капитала для финансирования ГРР.

- Чрезмерная закрытость геологической информации и предоставление ее исключительно на платной основе.

Геологическая информация, полученная за счет средств недропользователей, передается на хранение в государственные геологические фонды, но выдаются для ознакомления только по письменному разрешению владельца.

Подводя итоги исследования, можно сделать следующие выводы о целесообразности осуществления некоторых шагов по трансформированию системы геологоразведочной отрасли:

1. Совершенствование подходов к использованию государственного фонда недр.

В зависимости от степени изученности и объема бюджетных средств, вложенных в геологоразведочные работы, представляется целесообразным дифференцировать подход к распределению участков недрофонда. Так, участки категории P1 с разведанными и предварительно оцененными запасами могут быть отнесены к той части фонда, распределение которого может производиться в соответствии с ныне действующими правилами. Основная задачи государства при этом должна состоять в получении компенсации бюджетных средств, затраченных на геологоразведку. Вторую часть недрофонда могут составить все остальные участки. Здесь основной задачей государственного регулирования должно стать привлечение инвестиций в начальные стадии ГРР, поэтому оборот таких участков желательно сделать свободным.

2. Совершенствование системы лицензирования на проведение ГРР.

По нашему мнению, такие лицензии на право проведения ГРР на участках, относящихся ко второй части недрофонда, могут выдаваться на основании заявок потенциальных недропользователей. При этом какие-либо имущественные требования к недропользователю предъявлять нецелесообразно. Лицензия должна отражать право недропользователя на проведение ГРР и на разработку месторождения в случае его открытия. К числу же обязательств недропользователя следовало бы отнести минимальный уровень затрат средств на проведение ГРР и пре- доставление отчетности о них в строго регламентированной форме. Оборот лицензий желательно сделать свободным, а прекращение действия лицензии - осуществлять на основании решения суда при не достижении минимальных уровней инвестиций в ГРР и предоставлении некачественной отчетной информации.

3. Повышение мер государственной поддержки ГРР.

Такого рода поддержка должна осуществляться в сфере налогообложения и предусматривать полное или частичное освобождение от налога на прибыль средств, направляемых на цели геологоразведки. С целью привлечения сторонних инвесторов крайне желательным было бы также введение механизма переуступки налоговых льгот на инвестиции в ГРР.

4. Расширение участия частного капитала в финансировании ГРР.

С учетом повышенного риска геологоразведочного бизнеса данный аспект проблемы может быть реализован только путем создания системы рынков частного акционерного капитала. В развитых промышленных странах подобная форма привлечения инвестирования средств крупных и мелких вкладчиков довольно успешно существует в виде специальных инвестиционных фондов, площадок венчурного капитала и фондовых бирж. Разумеется, данное направление развития может быть реализовано только в случае обеспечения свободного получения и обращения прав на пользование недрами, освобождения от налога на прибыль средств, направляемых на ГРР и получения неограниченного доступа к геологической информации.

Подводя итоги, хочется выразить надежду, что комплекс предложенных мер окажет благоприятное воздействие на трансформацию геологической отрасли и окажет существенное влияние на ее поступательное развитие в деле обеспечения РФ необходимыми ресурсами и средствами для дальнейшего процветания. Данное актуальное направление исследования требует более детального и системного погружения с тем, чтобы по конкретным направлениям активности сформировать свои дорожные карты и внедрить их в реализацию на уровне государства и компаний. Такой системной работой в том числе планирует заниматься и авторский коллектив РГГРУ. 


\section{Библиографический список}

1. Архипов Г.И. Основы недропользования. Хабаровск. 2008. 353 с.

2. Варшавская И.Е., Волож Ю.А. и др. Новые подходы к решению проблемы роста ресурсной базы углеводородного сырья // Геология нефти и газа. № 2. 2011.

3. Государственный доклад «о состоянии и использовании минерально-сырьевых ресурсов РФ в 2016 и 2017 годах». Министерство природных ресурсов и экологии РФ.

4. Исаева Н.С. Оценка экономической эффективности эксплуатации минерально-сырьевой базы нефтегазовых компаний // Управление экономическими системами: электронный научный журнал. 2016. № 9.URL: http//www.uecs.ru.

5. Лютягин Д.В. Воспроизводство запасов минерально-сырьевой базы углеводородного сырья и стимулирование геологоразведочных работ / Доклады XIII Международной научно-практическая конференции «Новые идеи в науках о земле» 2017. Том 2. С. 277.

6. Мастепанов, А.M. Топливно-энергетический комплекс России на рубеже веков - состояние, проблемы и перспективы развития. Москва. 2009. 474 с.

7. Методические указания к разработке государственных планов экономического и социального развития СССР. Москва. 1980.

8. Панов Р.С. Развитие геологоразведки - залог стабильного экономического развития России // Аналитический вестник Совета Федерации Федерального собрания РФ «О состоянии геологического изучения недр и воспроизводства минерально-сырьевой базы» 2014. № 16 (354).

9. Пресс-конференция Заместителя Председателя Правления ПАО «Газпром» А.И. Медведева «Экспорт и повышение надежности поставок газа в Европу» URL: http://www.gazprom.ru/f/posts/86/062008/presentationpress-conf-2018-06-07-ru.pdf.

10. Распоряжение Правительства РФ от 21.06.2010 N1039-р «Об утверждении Стратегии развития геологической отрасли РФ до 2030 года».

11. Словарь современных экономических правовых терминов / авт.-сост. В.М. Мимов, А.Н. Тур, Н.В. Стах [и др.] Минск. 2002. 816 с.

12. Гаврилов В.П., Грунис Е.Б. Состояние ресурсной базы нефтедобычи в России и перспективы ее наращивания // Геология нефти и газа. 2012. № 5. С. 32-40.

13. Статистика // Бурение и нефть. 2017. № 2. С. 64.

14. Халимов Э.М., Гомзиков В.К., Фурсов А.Я. Управление запасами нефти. Москва. 1991.

15. Эдер Л.В., Филимонова В.Ю., Немов В.Ю. и др. Особенности современного развития газодобывающей промышленности России //Газовая промышленность. 2014. № 4. С. 8-14.

Поступила в редакцию 30.08.2018 